\title{
Enamel Deproteinization after Acid Etching - Is it Worth the Effort?
}

\section{Ramakrishna $\mathbf{Y}^{1 *}$, Bhoomika $\mathrm{A}^{2}$, Harleen $\mathrm{N}^{3}$ and Munshi $\mathrm{AK}^{1}$}

${ }^{1}$ Department of Pedodontics and Preventive Dentistry, K.D. Dental College and Hospital, Mathura, India

2 Department of Pedodontics and Preventive Dentistry, P.D.M Dental College and Hospital, Haryana, India

${ }^{3}$ Department of Pedodontics and Preventive Dentistry, Gurunanak Dev Dental College, Punjab, India

\begin{abstract}
Objectives: This study was undertaken to observe the topographical features of enamel surface deproteinized with $5.25 \%$ sodium hypochlorite $(\mathrm{NaOCl})$ after phosphoric acid $\left(\mathrm{H}_{3} \mathrm{PO}_{4}\right)$ etching using Scanning Electron Microscope (SEM) analysis and also the effect of enamel deproteinization after acid etching on the shear bond strength (SBS) of Adper $^{\mathrm{TM}}$ Single Bond 2 adhesive and Filtek ${ }^{\mathrm{TM}} \mathrm{Z}-350$ XT composite resin.

Study design: SEM Observation: 10 enamel blocks of $1 \mathrm{~mm}^{2}$ from 10 human sound permanent molar teeth were obtained and treated with $37 \% \mathrm{H}_{3} \mathrm{PO}$ gel for 15 seconds followed by treatment with $5.25 \% \mathrm{NaOCl}$ for 60 seconds. All the 10 samples were subjected to SEM analysis and 5 microphotographs of each sample were obtained at $500 \mathrm{X}$ magnification and evaluated for the occurrence of Type I - II etching pattern in percentage (\%) using Auto - CAD 2007 software. SBS Evaluation: A $5 \times 4 \mathrm{~mm}$ window of the enamel surface was etched with $37 \% \mathrm{H}_{3} \mathrm{PO}_{4}$ gel for 15 seconds, washed with distilled water and air dried. The etched enamel surface was then treated with $5.25 \% \mathrm{NaOCl}$ for 60 seconds, washed with distilled water and air dried. A single coat of Adper ${ }^{\mathrm{TM}}$ Single Bond 2 adhesive was applied and photo polymerized for 20 seconds and Filtek ${ }^{\mathrm{TM}} \mathrm{Z}-350$ XT composite resin block of length $5 \mathrm{~mm}$, width $4 \mathrm{~mm}$ and height $5 \mathrm{~mm}$ respectively was built and photo polymerized in increments for 20 seconds each. The shear bond strength of all the 20 test samples (permanent molar teeth) were measured (in MPa) on Instron Mechanical Testing Machine.
\end{abstract}

Results: The mean value of Type I - II etching pattern of all the test samples was observed to be $40.68+26.38 \%$ and the mean SBS value for all the test samples was observed to be $17.35+7.25 \mathrm{MPa}$.

Conclusions: No significant enhancive effect of enamel deproteinization after acid etching with respect to the occurrence of Type I-II etching patterns as well as on the SBS of adhesive resin and composite resin complex to the enamel surface was observed in this study. The use of $37 \%$ phosphoric acid alone for 15 seconds still remains the best method for pretreatment of the enamel.

Keywords: Adhesive; Composite resin; Enamel deproteinization; Etching; Phosphoric acid; Shear bond strength; Sodium hypochlorite

\section{Introduction}

To overcome the limitations of acid etching alone on the enamel surface various invasive and non-invasive techniques were introduced so as to enhance the effective bond between the enamel and the composite resin [1]. The concept of enamel deproteinization with $5.25 \%$ sodium hypochlorite $(\mathrm{NaOCl})$ before phosphoric acid $\left(\mathrm{H}_{3} \mathrm{PO}_{4}\right)$ etching and its effect on the etching patterns as well as on the shear bond strength of the adhesive system has been extensively studied by various authors [15]. Recently Matheus et al. [6] have tried 10\% papain gel as an enamel deproteinizing agent before bonding procedure and achieved good results with respect to the shear bond strength of orthodontic brackets bonded with resin-modified glass ionomer cement.

Theoretically contamination of the etched enamel surface should have a significant effect on the clinical outcome on the bond between the enamel and the composite resin. On the contrary enamel deproteinization with $5 \% \mathrm{NaOCl}$ after acid etching was first proposed by Venezie et al. [7] which resulted in an improved bonding of an orthodontic bracket to the hypomineralized enamel. The bond between the defective enamel and the restoration is highly dependent on the enamel surface alterations, removal of excess proteins may provide an advantage on the bonding of the restoration $[7,8]$. Sodium hypochlorite is known to be an excellent protein denaturant $[9,10]$. In this regard Venezie et al. [7] have concluded that treatment of hypocalcified amelogenesis imperfecta enamel with $5 \% \mathrm{NaOCl}$ after acid etching may be effective in deproteinization of the excess protein and enhancement of the bond strength [7].

In our two preceding studies $[4,5]$ we have evaluated the effect of $5.25 \% \mathrm{NaOCl}$ before acid etching and concluded that the use of $37 \%$ phosphoric acid alone still remains the best method for pretreatment of the enamel. To the best of our knowledge there is no report on the effect of $\mathrm{NaOCl}$ after acid etching on the etching patterns of the sound enamel surface available in the literature. Hence this study was conducted to evaluate the effect of $5.25 \% \mathrm{NaOCl}$ as an enamel deproteinizing agent after acid etching using scanning electron microscope analysis (SEM) and also the effect of enamel deproteinization after acid etching on the shear bond strength (SBS) of the adhesive resin and composite resin complex to the treated enamel surface.

\section{Materials and Method}

This study was partially carried out in the Department of Pedodontics and Preventive Dentistry, K. D. Dental College and Hospital, Mathura, India. The SEM Analysis was carried out at Sophisticated Analytical Instrument Facility for Electron Microscopy, Department of Anatomy, All India Institute of Medical Sciences (AIIMS), New Delhi, India and the Shear Bond Strength evaluation was carried out at Central Institute

${ }^{*}$ Corresponding author: Dr. Ramakrishna Yeluri. M.D.S, F.P.F.A, Professor Department of Pedodontics and Preventive Dentistry, K.D. Dental College and Hospital, Mathura - Delhi N.H \#2, Mathura - 281001, Uttar Pradesh, India, Tel +919997951558; Fax: 0565-2530764; E-mail: drramakrishnay@indiatimes.com, kittypedo@yahoo.com

Received December 17, 2013; Accepted Janaury 21, 2014; Published January 23, 2014

Citation: Ramakrishna Y, Bhoomika A, Harleen N, Munshi AK (2014) Enamel Deproteinization after Acid Etching - Is it Worth the Effort? Dentistry 4: 200 doi:10.4172/2161-1122.1000200

Copyright: (C) 2014 Ramakrishna Y, et al. This is an open-access article distributed under the terms of the Creative Commons Attribution License, which permits unrestricted use, distribution, and reproduction in any medium, provided the original author and source are credited. 
of Plastics Engineering and Technology (CIPET), Amritsar, Punjab, INDIA. Institutional Ethical Committee clearance was obtained prior to the beginning of this study. Informed written consent was also obtained from the patients who participated in this study.

The methodology followed in this study was similar to as suggested by Espinosa et al. [1] Bhoomika et al. [4] and Harleen et al. [5]. Thirty human sound permanent molars extracted for periodontal reasons were chosen from the patients attending the Department of Oral and Maxillofacial Surgery, K. D. Dental College and Hospital, Mathura, India. Immediately after extraction all the teeth were thoroughly washed in the running water to remove blood and any adherent tissue was removed using hand scalers. The teeth with enamel cracks or fractures along their buccal aspect, malformations, carious lesions, restorations or erosions were excluded from the study [1]. The crown portion of each tooth was polished with fluoride free pumice and rinsed with distilled water for 10 seconds. The extracted teeth were then stored in distilled water with thymol crystals added to it for a maximum of one week. Thereafter, they are stored in distilled water in a refrigerator until their use. The distilled water was changed weekly to minimize deterioration. All the teeth were collected, and utilized for the study within a span of four months [11].

\section{Specimen preparation and scanning electron microscopic observation}

10 permanent molars were randomly selected from the collected specimens and utilized for SEM analysis. The buccal surface of each crown was marked with 2 horizontal lines dividing the crown portion into 3 parts. Then 2 vertical lines were marked equidistant to each other and were cut with high speed double sided diamond disk (Shofu Inc., Kyoto, Japan) and trimmed to $1 \mathrm{~mm}^{2} .10$ enamel blocks of $1 \mathrm{~mm}^{2}$ obtained from the middle portion of all the teeth were utilized for SEM observation. All the blocks were observed under a stereomicroscope for any defects or cracks produced during the sectioning process. The enamel surface of each sample was etched with $37 \% \mathrm{H}_{3} \mathrm{PO}_{4}$ gel (Dentsply International, New Delhi, India) for 15 seconds, washed with sterile water and air spray for 10 seconds, then dried with oil free compressed air. The etched enamel surface was further treated with $5.25 \% \mathrm{NaOCl}$ (Prime Dent, Mumbai, India) applied with sterile cotton pellet for 60 seconds, washed with sterile water and air spray for 10 seconds, then dried with oil free compressed air. All the samples were then placed on stubs for gold sputtering and were coated with gold electrodepositing, using a Sputtering Effacoater (Agar Sputter Coater) and prepared for surface SEM analysis (LEO 435VP, Variable Pressure Scanning Electron Microscope, North Billerica, Massachusset). The observation zone [4] for all the samples was randomly selected at 5 different sites for each sample. Five microphotographs at 500X magnification were obtained from each enamel specimen covering the treated sample surface. A total of 50 images were obtained and evaluated for the quality of Type I-II etching [1] of the enamel surface in percentage for each sample using Auto-CAD 2007 software (Microsoft Corporation, Redmond, WA)

\section{Specimen preparation and shear bond strength evaluation [5]}

The remaining 20 permanent molars were utilized for SBS evaluation. The apices of all the teeth were sealed with sticky wax. Any visible water was removed by a light/brief stream of oil-free compressed air. An adhesive tape with a $5 \mathrm{~mm} / 4 \mathrm{~mm}$ rectangular window was applied to the buccal surface of the crown to delineate an area for surface treatment and bonding procedure.

The delineated enamel surface was etched with $37 \% \mathrm{H}_{3} \mathrm{PO}_{4}$ gel applied with a micro brush (3M ESPE, St. Paul, MN, USA) for 15 seconds, washed with distilled water and then dried with oil free compressed air for 10 seconds. The etched enamel surface was then treated with $5.25 \% \mathrm{NaOCl}$ applied with a sterile cotton pellet for 60 seconds, washed with distilled water and dried with oil free compressed air for 10 seconds. A single coat of Adper ${ }^{\text {rm }}$ Single Bond 2 adhesive (3M ESPE, St. Paul, MN, USA) was applied to the treated enamel surface according to the manufacturer's instructions and photo polymerized for 20 seconds. Filtek ${ }^{\text {Ta }}$ Z- 350 XT (3M ESPE, St. Paul, MN, USA) composite resin block of length $5 \mathrm{~mm}$, width $4 \mathrm{~mm}$ and height $5 \mathrm{~mm}$ respectively was built on the bonded surface and photo polymerized in increments for 20 seconds each.

Each tooth was then mounted in stainless steel molds of height $1 \frac{1}{2}$ inches and diameter of $2.5 \mathrm{~cm}$ containing self cure acrylic resin (Dental Products of India, Mumbai, India). The teeth were aligned with in the molds so that their buccal surface of the crowns was exposed such that the composite block was $1 \mathrm{~mm}$ above the mounting surface [11] and paralled the force during shear bond strength testing. The mounted teeth were then placed immediately in water to reduce the heat generated by polymerization reaction.

All the test samples were stored in water for $24 \mathrm{hrs}$ at $37^{\circ} \mathrm{C}$ prior to testing (Test type-1) [11]. The shear bond strength of all the samples were measured on Instron Mechanical Testing Machine (LR - 100K, Lloyd Instruments, West Sussex, U.K.) using a stainless steel shear probe. The specimens were tested using a cross head displacement rate of $0.5 \mathrm{~mm} /$ minute [11]. The minimum load required to produce the bond failure was determined from the first load drop on the load deflection plot. Shear bond strength values were calculated in megapascals (MPa) [11]

The data thus obtained from both the parameters were compared with our previous published data [4,5] (Acid etching alone, Deproteinization before acid etching) to evaluate the effect of deproteinization after acid etching of the enamel surface.

\section{Results}

The distribution of Type I-II etching pattern in percentage obtained for the 10 enamel blocks are shown in Table 1 and the mean value of all the samples was observed to be $40.68+26.38 \%$ which was significantly less (ANOVA, $\mathrm{p}<0.05)$ when compared with etching alone [4] (55.76 $+25.47 \%)$ [4] and deproteinization before acid etching [4] (53.58 $+22.47 \%$ ) [4]. It is evident from Figure 1 that the occurrence of

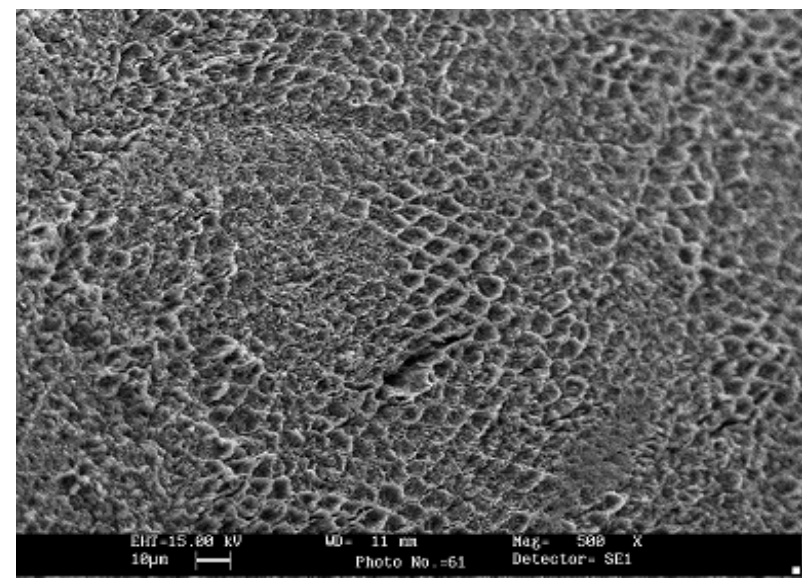

Figure 1: SEM picture of the enamel surface deproteinized after acid etching showing indiscriminate type of etching pattern dominating the Type I-I pattern (Original Magnification X 500) 


\begin{tabular}{|c|c|c|c|}
\hline Sample No. & $\begin{array}{c}\text { No. of } \\
\text { Microphotographs }\end{array}$ & $\begin{array}{l}\text { Type I - II etching } \\
\text { Pattern }\end{array}$ & $\begin{array}{c}\text { Average per } \\
\text { sample }\end{array}$ \\
\hline \multirow[t]{5}{*}{ Sample 1} & 1 & $4 \%$ & \\
\hline & 2 & $3 \%$ & \\
\hline & 3 & $7 \%$ & \\
\hline & 4 & $3 \%$ & \\
\hline & 5 & $3 \%$ & $4 \%$ \\
\hline \multirow[t]{5}{*}{ Sample 2} & 1 & $46 \%$ & \\
\hline & 2 & $36 \%$ & \\
\hline & 3 & $37 \%$ & \\
\hline & 4 & $41 \%$ & \\
\hline & 5 & $43 \%$ & $49.6 \%$ \\
\hline \multirow[t]{5}{*}{ Sample 3} & 1 & $72 \%$ & \\
\hline & 2 & $52 \%$ & \\
\hline & 3 & $64 \%$ & \\
\hline & 4 & $79 \%$ & \\
\hline & 5 & $82 \%$ & $69.8 \%$ \\
\hline \multirow[t]{5}{*}{ Sample 4} & 1 & $82 \%$ & \\
\hline & 2 & $76 \%$ & \\
\hline & 3 & $61 \%$ & \\
\hline & 4 & $58 \%$ & \\
\hline & 5 & $51 \%$ & $65.6 \%$ \\
\hline \multirow[t]{5}{*}{ Sample 5} & 1 & $25 \%$ & \\
\hline & 2 & 0 & \\
\hline & 3 & $32 \%$ & \\
\hline & 4 & $77 \%$ & \\
\hline & 5 & $74 \%$ & $41.6 \%$ \\
\hline \multirow[t]{5}{*}{ Sample 6} & 1 & $29 \%$ & \\
\hline & 2 & $31 \%$ & \\
\hline & 3 & $18 \%$ & \\
\hline & 4 & $17 \%$ & \\
\hline & 5 & $20 \%$ & $23 \%$ \\
\hline \multirow[t]{5}{*}{ Sample 7} & 1 & $27 \%$ & \\
\hline & 2 & $30 \%$ & \\
\hline & 3 & $36 \%$ & \\
\hline & 4 & $41 \%$ & \\
\hline & 5 & $35 \%$ & $33.8 \%$ \\
\hline \multirow[t]{5}{*}{ Sample 8} & 1 & $60 \%$ & \\
\hline & 2 & $77 \%$ & \\
\hline & 3 & $79 \%$ & \\
\hline & 4 & $59 \%$ & \\
\hline & 5 & $49 \%$ & $64.8 \%$ \\
\hline \multirow[t]{4}{*}{ Sample 9} & 1 & $0 \%$ & \\
\hline & 2 & $7 \%$ & \\
\hline & 3 & $6 \%$ & \\
\hline & 4 & $6 \%$ & \\
\hline
\end{tabular}

\begin{tabular}{|l|l|l|c|}
\hline & 5 & $6 \%$ & $\mathbf{5} \%$ \\
\hline Sample 10 & 1 & $42 \%$ & \\
\hline & 2 & $69 \%$ & \\
\hline & 3 & $61 \%$ & \\
\hline & 5 & $61 \%$ & $\mathbf{5 9 . 8} \%$ \\
\hline Mean & & $66 \%$ & $\mathbf{4 0 . 6 8} \mathbf{2 6 . 3 8} \%$ \\
\hline
\end{tabular}

Table 1: Percentage distribution of Type I -Type II etching pattern observed at 5 different sites in each sample.

\begin{tabular}{|c|c|}
\hline Test Sample No. & $\begin{array}{c}\text { Shear Bond Strength } \\
\text { (MPa) }\end{array}$ \\
\hline 1 & 19.56 \\
\hline 2 & 17.12 \\
\hline 3 & 15.65 \\
\hline 4 & 13.33 \\
\hline 5 & 9.36 \\
\hline 6 & 11.93 \\
\hline 7 & 8.18 \\
\hline 8 & 21.32 \\
\hline 9 & 17.54 \\
\hline 10 & 25.17 \\
\hline 11 & 17.48 \\
\hline 12 & 40.74 \\
\hline 13 & 8.86 \\
\hline 14 & 11.47 \\
\hline 15 & 22.46 \\
\hline 16 & 13.74 \\
\hline 17 & 18.62 \\
\hline 18 & 21.22 \\
\hline 19 & 16.15 \\
\hline 20 & 17.12 \\
\hline Mean (MPa) & $17.35 \pm 7.215$ \\
\hline
\end{tabular}

Table 2: Mean shear bond strength value of the test samples.

indiscriminate type of etching pattern is more than the ideal Type I - II etching pattern required for a good bond. The individual values of SBS obtained for the 20 test samples are shown in Table 2 and the mean SBS was observed to be $17.35+7.215 \mathrm{MPa}$ which was statistically not significant (ANOVA, $p>0.05$ ) when compared with acid etching alone [5] $(13.51+5.726 \mathrm{MPa})[5]$ and deproteinization before acid etching [5] $(15.06+6.220 \mathrm{MPa})[5]$.

\section{Discussion}

Enamel etching transforms the smooth enamel surface into an irregular surface with a high surface energy $(72$ dynes $/ \mathrm{cm})$ more than twice that of unetched enamel [12]. An unfilled resin with low viscosity, the adhesive resin, wets the high energy surface and is drawn into the micro porosities by capillary action. With the purpose of eliminating the influence of the organic content on the adhesion of composites to the enamel surface various studies [1-5] have been tried and resulted in contradictory conclusions. Recently Gandhi et al. [13] concluded from their study that there was no significant difference in the tag quality between the conventional technique and the "bleach-etch-seal" (Deproteinization before acid etching) technique.

The concept of enamel deproteinization and its effect on the etching patterns was first described by Espinosa et al. [1] in the year 
2008 and further excellent resin replica [3] of the same concept proved that enamel deproteinization prior to $\mathrm{H}_{3} \mathrm{PO}_{4}$ etching almost doubles enamel's retentive surface by increasing the occurrence of Type I-II etching patterns. Roberto et al. [2] also concluded that the elimination of organic substances from the enamel surface before acid etching increases the resistance to orthodontic traction by providing a better acid etching pattern on the enamel surface. But the effect of $\mathrm{NaOCl}$ on the organic content after acid etching has not been tried before. Enamel deproteinization with $\mathrm{NaOCl}$ after acid etching was in clinical use since it was first described by Venezie et al. [7] in 1994. We predicted that after acid etching there might be a possibility of better penetration and action of $\mathrm{NaOCl}$ on the organic content of the etched patterns already obtained, thereby enhancing the final clinical outcome i.e. enhanced bond strength between the composite resin complex and the treated enamel surface. The Type I-II etching pattern for these samples was observed to be $40.68+26.38 \%$, which was far inferior to etching alone [4] and deproteinization before acid etching [5]. Even though the mean SBS value obtained in this study was more than the previous study [5] it was statistically not significant. The observations of this study further strengthen the conclusions of our previous studies [4,5] regarding the role of $5.25 \% \mathrm{NaOCl}$ enamel deproteinization.

Recently $10 \%$ papain has been tried as a deproteinizing agent with good results. Papain is a major constituent of Papacaire: a chemo mechanical caries removal agent which is routinely used in Pediatric Dentistry. Hence further studies are also needed in determining the role of newer agents. Enamel deproteinization may be benefitted in cases like Molar Incisor Hypo mineralization (MIH) and Amelogenesis Imperfecta (AI) where there may be $3-4 \%$ protein by weight compared with $0.5 \%$ for normal enamel $[7,8]$. This study has evaluated the effect of $\mathrm{NaOCl}$ on the sound enamel surface. This agent might prove to be useful in cases where organic content is more. Şaroğlu et al. [14] in their study concluded that deproteinization after acid etching could be attributed as effective in enhancing the enamel bonding in HCAI teeth and could be used to overcome the high failure rates of adhesive restorations in Hypo calcified Amelogenesis Imperfecta (HCAI) cases. But Sönmez et al. [15] have observed that enamel deproteinization after acid etching had no significant effect on the success of the adhesive restorations; however, composite restorations were found to be clinically successful in children affected by HCAI in long term follow-up. Kotsanos et al. [16] found that MIH teeth were eleven times more likely to undergo restorative treatments on at least one-first permanent molar and were three times more at risk of their 'fillings and sealants' failing, whereas Lygidakis et al. [17] have reported that only a quarter of fissure sealants remained on MIH teeth four years after application. It has been shown that the enamel-resin interface for MIH enamel is weak in comparison with sound enamel, possibly due to the limited inter-rod dissolution, intercrystal porosity, and micro tag formation seen in $\mathrm{MIH}$ enamel [18]. The high organic content seen in $\mathrm{MIH}$, as well as the poor bond between its enamel-resin interfaces, has led to similarities being drawn between the composition, treatment, and management of AI affected enamel $[19,20]$. It has been shown in numerous studies that, as a result of its protein denaturing ability, 'bleach' pretreatment in the form of $5 \% \mathrm{NaOCl}$ can have a beneficial effect on the enamel-resin interface of AI and dysmineralized teeth $[7,19,20]$. Hence further studies are also needed in evaluating the effect of $\mathrm{NaOCl}$ if any after acid etching in teeth where organic content is more.

\section{Conclusions}

The conclusions drawn from this study are

1. Enamel deproteinization after $37 \% \mathrm{H}_{3} \mathrm{PO}_{4}$ etching resulted in
$40.68 \%$ of Type I-II etching patterns on the enamel surface

2. There was no enhancive effect of enamel deproteinization after acid etching on the shear bond strength of adhesive resin and composite resin complex to the treated enamel surface.

3. According to the results of this study, it can be concluded that the use of $37 \%$ phosphoric acid for 15 seconds still remains the best method for pretreatment of the enamel.

\section{References}

1. Espinosa R, Valencia R, Uribe M, Ceja I, Saadia M (2008) Enamel deproteinization and its effect on acid etching: An in vitro study. J Clin Pediatr Dent 33: 13-19.

2. Roberto J, Tatiana C, Ricardo O, Fernando M (2010) A new technique with sodium hypochlorite to increase bracket shear bond strength of fluoride releasing resin modified glass ionomer cements: Comparing shear bond strength of two adhesive systems with enamel surface deproteinization before etching. Sem In Orthod 16: 66-75.

3. Espinosa R, Valencia R, Uribe M, Ceja I, Cruz J, et al. (2010) Resin replica in enamel deproteinization and its effect on acid etching. $\mathrm{J}$ Clin Pediatr Dent 35: 47-52.

4. Ahuja B, Yeluri R, Baliga S, Munshi AK (2010) Enamel deproteinization before acid etching - A Scanning electron microscopic observation. J Clin Pediatr Dent 35: 169-172.

5. Harleen N, Ramakrishna Y, Munshi AK (2011) Enamel deproteinization before acid etching and its effect on the shear bond strength - An in vitro Study. $\mathrm{J}$ Clin Pediatr Dent 36: 19-24.

6. Pithon MM, Ferraz C, Oliveira G, Pereira TBJ, Oliveira D, et al. (2012) Effect of $10 \%$ papain gel on enamel deproteinization before bonding procedure. Angle Orthodont 82: 541-545.

7. Venezie RD, Vadiakas G, Christensen JR, Wright JT (1994) Ename pretreatment with sodium hypochlorite to enhance bonding in hypocalcified amelogenesis imperfecta: case report and SEM analysis. Pediatr Dent 16: 433 436.

8. Wright JT, Duggal MS, Robinson C, Kirkham J, Shore R (1993) The minera composition and enamel ultrastructure of hypocalcified amelogenesis imperfecta. J Craniofac Genet Dev Biol 13: 117-126.

9. Inaba D, Duschner H, Jongebloed W, Odelius H, Takagi O, et al. (1995) The effects of a sodium hypochlorite treatment on demineralized root dentin. Eur $\mathrm{J}$ Oral Sci 103: 368-374

10. Perdigão J, Lopes M, Geraldeli S, Lopes GC, García-Godoy F (2000) Effect of a sodium hypochlorite gel on dentin bonding. Dent Mater 16: 311-323.

11. International Organization for Standardization (2003) ISO/ Technical specifications 11405: Dental Materials - Testing of adhesion to tooth structure.

12. Jendresen MD, Glantz PO, Baier RE, Eick JD (1981) Microtopography and clinical adhesiveness of an acid etched tooth surface. Acta Odontol Scand 39: 47-53.

13. Gandhi S, Crawford P, Shellis $P$ (2012) The use of a 'bleach - etch - seal' deproteinization technique on MIH affected enamel. Int J Pediatr Dent 22: 427434.

14. Şaroğlu I, Aras Ş, Öztaş D (2006) Effect of deproteinization on composite bond strength in hypocalcified amelogenesis imperfecta. Oral Dis 12: 305-308.

15. Sönmez IŞ, Aras Ş, Tunç EŞ, Küçükeşmen Ç (2009) Clinical success of deproteinization in hypocalcified amelogenesis imperfecta. Quintessence Int 40: 113-118.

16. Kotsanos N, Kaklamanos EG, Arapostathis K (2005) Treatment managemen of first permanent molars in children with molar - incisor hypomineralization. Eur J Paediatr Dent 6: 179-184.

17. Lygidakis NA, Dimou G, Stamataki E (2009) Retention of fissure sealants using two different methods of application in teeth with hypomineralised molars (MIH): a 4 year clinical study. Eur Arch Paediatr Dent 10: 223-226.

18. William V, Burrow MF, Palamara JE, Messer LB (2006) Microshear bond strength of resin composite to teeth affected by molar hypomineralization using 2 adhesive systems. Pediatr Dent 28: 233-241. 
Citation: Ramakrishna Y, Bhoomika A, Harleen N, Munshi AK (2014) Enamel Deproteinization after Acid Etching - Is it Worth the Effort? Dentistry 4: 200. doi:10.4172/2161-1122.1000200

Page 5 of 5

19. Wright JT (2002) The etch-bleach-seal technique for managing stained ename defects in young permanent incisors. Pediatr Dent 24: 249-252.
20. William V, Messer LB, Burrow MF (2006) Molar incisor hypomineralization review and recommendations for clinical management. Pediatr Dent 28: 224-232. 